\title{
Anticancer activities and mechanisms of heat-clearing and detoxicating traditional Chinese herbal medicine
}

\author{
Yulin Zhang ${ }^{\dagger}$, Yeer Liang ${ }^{\dagger}$ and Chengwei $\mathrm{He}^{*}$ (D)
}

\begin{abstract}
In traditional Chinese medicine (TCM) theory, pathogenic heat and toxins, which are akin to the inflammatory factors, are the causes of cancer and could promote its virulent development. Therefore, heat-clearing and detoxicating (HCD) herbs are essential components of TCM formulas for cancer treatment. An increasing interest has been focused on the study of HCD herbs and accumulated evidences have shown that HCD herbs or HCD herbs-based formulas exhibited remarkable anticancer effects when used alone or combined with other therapeutic approaches. Some of the HCD herb-derived products have been tested in clinical trials. Studies revealed that extracts or pure compounds of the HCD herbs showed a broad anticancer spectrum against both solid and hematologic malignancies without significant toxic effects. Notably, some HCD herbs or formulas could strongly enhance the anticancer activities of chemo- or radio-therapy and alleviate their side effects. The anticancer activities of HCD herb exacts or the pure compounds were reported to be through multiple cellular or molecular mechanisms, such as induction of cancer cell apoptosis, differentiation and cell cycle arrest, inhibition of cancer cell growth, invasion and metastasis, and inhibition of tumor angiogenesis. In this review, we provide comprehensive analysis and summary of research progress and future prospects in this field to facilitate the further study and application of HCD herbs.
\end{abstract}

Keywords: Traditional Chinese medicine, Heat-clearing and detoxicating herbs, Anticancer, cellular and molecular mechanisms

\section{Background}

Cancers have been becoming one of the top killers worldwide. There were approximately 14.1 million new cancer cases and 8.2 million deaths from cancers in the world in 2012 according to the WHO statistics. Cancer still viciously scares people more than any other diseases despite substantial development of cancer diagnosis and treatment has been made. The majority of cancer patients are often diagnosed after the cancer has reached a terminal stage, at which chemotherapy is largely relied on. Although chemotherapy may temporarily slow tumor growth, they often lose the effectiveness as

\footnotetext{
*Correspondence: chengweihe@umac.mo

${ }^{\dagger}$ Yulin Zhang and Yeer Liang contributed equally to this work State Key Laboratory of Quality Research in Chinese Medicine, Institute of Chinese Medical Sciences, University of Macau, N22-7038, Avenida da Universidade, Taipa, Macao 999078, China
}

the cancer cells develop drug resistant. Some remedies may not be suitable for long-term use due to severe side effects. Thus, it is important to develop novel effective and safe approaches for cancer treatment. Comparing to modern Western medicine, traditional Chinese medicine (TCM) comprises a particularly safe and effective strategy in the treatment of cancer. In TCM theory, disequilibrium between Yin and Yang and blockage of meridian and viscera caused by interior (long time stress, anxiety, depress, overwork, improper lifestyle, etc.) and exterior factors (physical and chemical hazards) leads to stasis of Chi (vital energy), blood, dampness and phlegm, where the pathogenic heat and toxins, which are similar to the factors that cause prominent inflammation, are generated and promote occurrence and development of cancer eventually after these long-lasting malfunctions. Therefore, heat-clearing and detoxicating (HCD) herbs, 
Chi-regulating herbs, circulation-enhancing herbs, dampness and phlegm-resolving herbs are often used to treat cancers in TCM. HCD herbs are mostly cold in nature and bitter in taste and commonly used to clear away heat, purge fire, dry dampness and cool blood, and relieve toxins. Since pathogenic heat and toxins are more directly related to cancer, HCD herbs or formulas play a predominant role in cancer management by TCM. This review aims to summarize the representative anticancer HCD herbs and formulas, with emphasis on discussing the anticancer activities and the molecular mechanisms.

\section{Representative anticancer HCD herbs}

The following representative anticancer HCD herbs are discussed in details: Scutellariae Radix (Huang Qin), Coptidis Rhizome (Huang Lian), Artemisiae annuae Herba (Qing Hao), Hedyotis diffusa (Bai Hua She She Cao), Rabdosiae rubescentis Herba (Dong Ling Cao), and Scutellariae barbatae Herba (Ban Zhi Lian), which are very commonly prescribed HCD herbs in the anticancer TCM formulas and have been extensively studied.

\section{Scutellariae Radix}

Scutellariae Radix (SR) is the dried root of Scutellaria baicalensis Georgi of the Lamiaceae family. SR is traditionally used to clear away pathogenic heat and activate blood circulation to remove stasis. Clinically, SR has long been used to treat pneumonia, jaundice, hypertension, dysentery and intestinal catarrh, pyogenic infection, etc. It is often prescribed in combination with other herbs in TCM formulas, such as Huang Qin Tang, Huang Qin Shao Yao Tang, and Huang Qin Mu Dan Tang. The most abundant compounds in SR are flavonoids, of which baicalein, baicalin, wogonoside and wogonin (Fig. 1a-d) showed strong anticancer activities.

Baicalein, the major flavone in SR, exhibited multiple pharmacological activities, such as anti-hepatotoxicity, anti-viral, anti-inflammation, and anticancer. Baicalein was reported to have anticancer activity against a wide spectrum of cancers [1], including esophagus, gastric, colorectal, pancreatic, lung, breast, ovarian, prostate and skin cancers $[2,3]$. The anticancer activity of baicalein was through multiple mechanisms, e.g. suppressing hyperproliferation, inflammation, and metastasis, inducing apoptosis, etc. [3, 4], in which the PI3K/Akt and p38 pathways were engaged [5].

Wogonin, another flavone derived from SR, was proved to be effective in anticancer both in vitro and in mouse models, through inducing apoptosis, cell cycle arrest, and differentiation of cancer cells, inhibiting angiogenesis of tumor, and reversing drug resistance. Polier et al. reported that wogonin specifically inhibited the activity of cyclindependent kinase 9 (CDK9) and down-regulated the short-lived anti-apoptotic protein myeloid cell leukemia 1 (Mcl-1), which resulted in apoptosis in cancer cells [6]. Wogonin also induced nasopharyngeal carcinoma (NPC) cell apoptosis via inhibiting the activity of glycogen synthase kinase $3 \beta$ (GSK-3 $\beta$ ), a multifunctional serine/threonine kinase that was reported to inhibit apoptosis, and down-regulating the expression of $\Delta \mathrm{Np} 63$, a survival factor in NPC cells [7]. In addition, wogonin inhibited tumor angiogenesis by promoting the degradation of hypoxiainducible factors $\alpha$ (HIF-1 $\alpha)$ via increasing its prolyl hydroxylation [8]. Acquired drug resistance is a serious problem in cancer treatment. Wogonin could reverse drug resistance in MCF-7/DOX cells through inhibiting the cell survival factors nuclear factor erythroid 2-related factor 2 (Nrf2) and heme oxygenase-1 (HO-1) [9]. Notably, wogonin significantly potentiated etoposide-induced apoptosis by impairing the function of P-glycoprotein and then increased cellular content of etoposide in HL-60 cells [10]. This synergistic effects were also observed when combination with fluorouracil in human gastric model. The synergistic anticancer activity of wogonin could be due to its pro-apoptotic effect and downregulation of NF- $k B$ [11]. Furthermore, wogonin preferentially killed cancer cells instead of influence on normal cells. Based on these researches, Scutellariae radix and its effective constituents may serve as a clinically potential therapeutic agents against aggressive malignancies.

\section{Coptidis Rhizoma}

Coptidis Rhizoma (CR) is the dried rhizome of Coptis Chinese Franch. of the Ranunculaceae family. The properties of CR are: extremely bitter and cold in nature, very strong in clearing heat and dampness, and detoxication. CR is commonly used in China for the treatment of gastroenteritis, liver disease, hypertension, and other inflammatory diseases accompanied by high fever. CR or its components were found to be beneficial for a wide range of diseases, such as diarrhea, pressure-overload induced cardiac hypertrophy, hypercholesterolemia, atherosclerosis, Alzheimer's disease, and diabetes mellitus. Interestingly, our studies and others demonstrated that $\mathrm{CR}$ extract exhibited strong anticancer effects in vitro and in vivo used alone or combined with chemotherapeutic drugs [12-14]. CR extract significantly inhibited tumor growth and colony formation of gastric, colon, and breast cancer cells. Breast cancer cells were particularly sensitive to CR. The growth inhibition was associated with suppression of cyclin B1 protein, which resulted in complete inhibition of $\mathrm{CDC} 2$ kinase activity and cell cycle arrest at $G_{2}$ phase [15]. Iizuka and his colleagues reported that the aqueous extract of $C R$ exhibited inhibitory effect on the proliferation of esophageal cancer cells and arrested the cells at $G_{0} / G_{1}$ phase [16]. CR 
Zhang et al. Chin Med (2017) 12:20

Page 3 of 15

$\mathbf{a}$<smiles>O=c1cc(-c2ccccc2)oc2cc(O)c(O)c(O)c12</smiles>

Baicalein

e<smiles>COc1ccc2cc3[n+](cc2c1OC)CCc1cc2c(cc1-3)OCO2</smiles>

Berberine

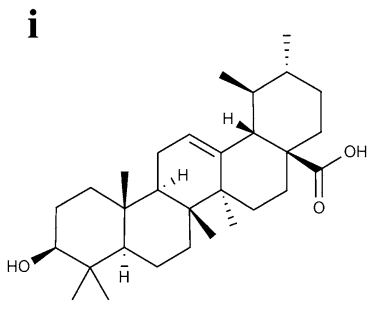

Ursolic acid

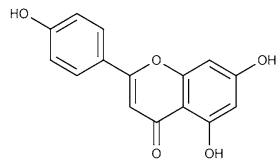

Apigenin

$\mathbf{q}$

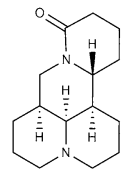

Matrine

$\mathbf{r}$ b<smiles>O=C(O)[C@H]1O[C@@H](Oc2cc3oc(-c4ccccc4)cc(=O)c3c(O)c2O)[C@H](O)[C@@H](O)[C@@H]1O</smiles>

Baicalin

f

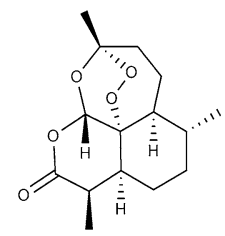

Aremisinin

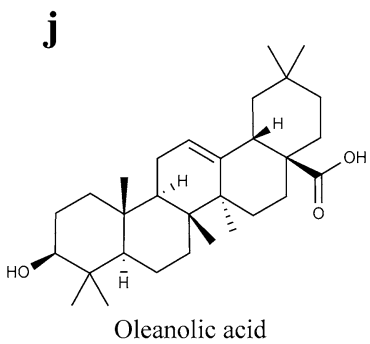

n

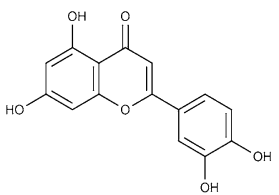

Luteolin

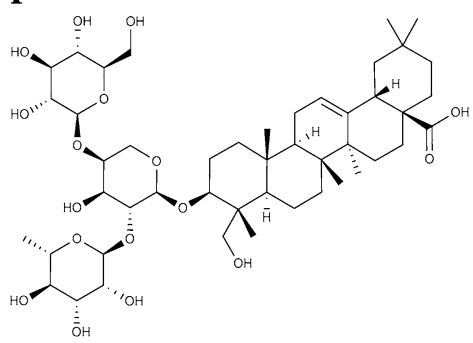

Saponin D<smiles>COc1c([C@](O)(C=O)[C@@H](O)[C@H](O)[C@H](O)C(=O)O)cc(O)c2c(=O)cc(-c3ccccc3)oc12</smiles>

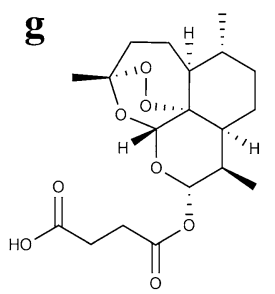

Artesunate

k<smiles>Cc1cccc2c1C(=O)c1ccccc1C2=O</smiles>

Methylanthraquinone

$\mathbf{0}$
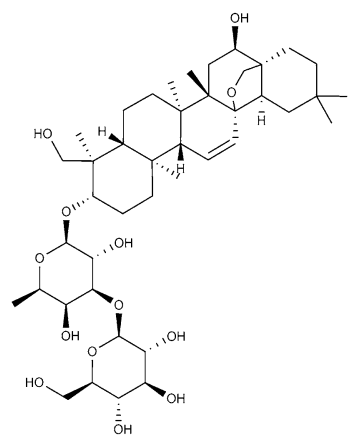

Saikosaponin D

S

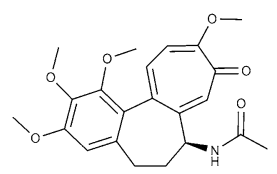

Colchicine d<smiles>COc1c(O)cc(O)c2c(=O)cc(-c3ccccc3)oc12</smiles>

Wogonin

h

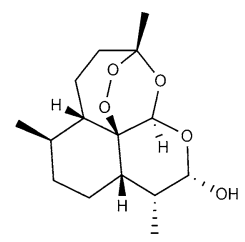

Dihydroartemisinin

I

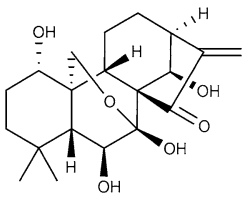

Oridonin

p

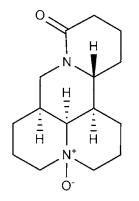

Oxymatrine

$\mathbf{t}$

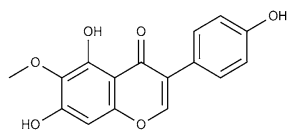

Tectorigenin

Fig. 1 Chemical structures of major anticancer compounds in the representative HCD herbs 
supplementation significantly attenuated weight loss in tumor-bearing nude mice without changing food intake or tumor growth, and maintained good nutritional status in these mice. The anti-cachectic effect was accompanied by significantly reduced interleukin 6 (IL-6) expression [17].

The most abundant compounds in CR are alkaloids, of which berberine (Fig. 1e) is the most important active compound, with its dry weight consisting of up to $7.1 \mathrm{mg} / 100 \mathrm{mg}$ of CR [18]. Recent data have shown that berberine was applied in treating inflammation, cancer, colitis, diabetes, high blood cholesterol etc. [19]. Considerable attention has been drawn to berberine since its prominent anticancer activity including tongue squamous cancer, esophageal cancer, hepatocelluar cancer, breast cancer, lung cancer, gastric cancer, ovarian cancer, renal cancer, nasopharyngeal cancer and Wilms' tumor [20]. Berberine has been proved to be a heat-clearing and detoxifying compound which acts on diverse cancer cell types through various mechanisms. For the treatment of colorectal cancer, berberine was mainly involved in inducing apoptosis and restraining inflammation, inhibiting tumor growth, inactivating $\mathrm{Wnt} / \beta$-catenin signaling, promoting the generation of ROS, inhibiting arylamine $\mathrm{N}$-acetyltransferase (NAT) activity and cyclooxygenase 2 (COX-2) expression [21]. Interestingly, berberine significantly reduced the familial adenomatous polyposis patients' polyp size through inhibition of Wnt signaling, suggesting an application in the prevention of colon cancer [22]. Berberine also suppresses the invasive and metastasis of nasopharyngeal carcinoma (NPC) by inhibiting the activation of Signal Transducer and Activator of Transcription 3 (STAT3), a key mediator to trigger tumor-promoting inflammation [23]. The similar actions were observed in lung cancer, of which cell proliferation and tumor spheroid formation were suppressed by berberine [24]. Notably, berberine exhibits selective cytotoxicity against cancer cells instead of normal hepatocytes [25]. In human breast cancer cells, berberine induces apoptosis through a mitochondrial dependent pathway by increasing the $\mathrm{Bax} / \mathrm{Bcl}-2$ protein ratio, activating caspases and inducing poly (ADP-ribose) polymerase (PARP) cleavage [26]. The induction of interferon $\beta$ and tumor necrosis factor (TNF) $\alpha$ in cancer cells is responsible for the anti-breast cancer activity of berberine [13]. Furthermore, berberine significantly enhanced the anticancer effect of estrogen receptor (ER) antagonists on ER positive breast cancer cells through down-regulating the expression of cancer related genes, such as epidermal growth factor receptor (EGFR), human epidermal growth factor receptor 2 (HER2), and bcl-2 [14]. Improvement of the chemo- and radio-sensitivity of tumors by herbs indicates another strategy of treatment in cancer therapy.
Anticancer efficacy was significantly enhanced when combining berberine with granted chemotherapeutic agents such as vincristine or 2-deoxy-D-glucose in certain cancer cells [27]. Combined with $\gamma$ radiation, berberine exhibited pro-apoptotic effect in hepatocellular carcinoma cells [28]. The chemosensitization of berberine was showed in colon cancer cells while the radiosensitization was obtained in esophageal squamous carcinoma cells, human nasopharyngeal carcinoma cells, and breast carcinoma cells $[29,30]$. It's important to note that berberine has so poor bioavailability that it can hardly be an independent anti-tumor agent [31]. Nevertheless, berberine could be a promising adjuvant to chemotherapy and radiotherapy of a wide range of cancers.

\section{Artemisiae annuae Herba}

Artemisiae annuae Herba (AAH) is the dried aerial part of Artemisia annua L. of the Compositae family. It was initially used for treating fevers in TCM, and was then renowned to be an antimalarial herb. Recent studies indicated that AAH showed high potential anticancer activities [32].

The most abundant compounds in AAH are sesquiterpene lactones, of which artemisinin (Fig. 1f) is the most active compound. Artemisinin has a broad range of biological activities, such as anti-viral, anti-fungal, antiparasitic, anti-inflammation, and anticancer. The anticancer activities of artemisinin include anti-proliferation, anti-angiogenesis, anti-invasion, anti-metastasis and cytotoxicity [33]. Artemisinin and its derivatives, such as artesunate (Fig. 1g) and dihydroartemisinin (DHA) (Fig. 1h), exhibit potential anticancer effects on various types of cancer cells, including breast cancer, leukemia, ovarian cancer, hematoma, prostate cancer, colon cancer, gastric cancer, melanoma and lung cancer [34]. Artemisinin was reported to inhibit angiogenesis through down-regulating the expression of vascular endothelial growth factor (VEGF), a key angiogenesis stimulator, in in vitro and in vivo assays [35]. Artemisinin induced a strong stringent G1 cell cycle arrest in prostate cancer cells, human breast cancer cells and nasopharyngeal cancer cells by down-regulating the expression of CDK2, CDK4, cyclin E, cyclin D1 and E2F1, and increasing the expression of p16 (also known as cyclin-dependent kinase inhibitor 2A) [36]. DHA treatment caused cervical cancer cell growth inhibition via upregulation of Raf kinase inhibitor protein (RKIP) and downregulation of bcl-2 [37]. Artemisinin can alter apoptosis-related protein expression which may further inhibit cell proliferation and induce apoptosis. Artemisinin downregulated IGF-IR expression and inhibited the growth of MCF-7 breast tumor cell xenografts in nude mice [38]. Moreover, the inhibition of Bcl-2 family, activation of Bax and 
release of cytochrome $\mathrm{c}$ in human colon cancer cells illuminate the pro-apoptotic mechanisms of artemisinin [39]. Artemisinin may also be a potential anti-metastasis agent against melanoma cells and hepatocarcinoma cells by reducing MMP2 level [40]. A more recent report revealed that DHA activates the autophagy program by suppressing the nuclear translocation of NF- $\mathrm{kB}$ [41]. In vivo experiments showed that oral administration of artemisinin at $50 \mathrm{mg} / \mathrm{kg} /$ day decreased tumor growth [40]. The toxicity of artemisinin remains a challenge for its development in the clinical application. In addition to possessing cytotoxicity in various tumors, artemisinin shows slight neurotoxicity and may cause drug resistance in vivo [33]. Besides, artemisinin and its derivatives produce synergistic anticancer effects in combination with other chemotherapeutic drugs. For instance, DHA sensitized human ovarian cancer cells to carboplatin therapy and synergistically enhanced the anticancer effect of gemcitabine on human lung cancer cells [42, 43].

\section{Hedyotis diffusa}

Hedyotis diffusa (HD) is the dried whole plant of genus Saxifraga of the Rubiaceae family. As a well-known traditional Chinese folk medicine, it frequently appears in Chinese medicinal formulas and has long been used for heat-clearing, detoxification, promotion of blood circulation and removal of blood stasis [44]. Accumulating evidences indicate that HD possesses anticancer, antioxidative, hepatoprotective, neuroprotective, antiinflammatory, anti-mutagenesis and immunoregulatory activities [45]. It is applied in the treatment of inflammation-related diseases, such as appendicitis, bronchitis and urethritis. Pharmacological studies propose that HD performs vital roles in the treatment of solid tumors, including liver, lung, colon, and other cancers [46]. Both organic and aqueous extracts of HD exhibit remarkable anticancer activities. The methanol extracts of HD can suppress cancer cell proliferation and induce apoptosis, which involve many tumor-related genes and proteins (e.g. TNF- $\alpha$, IL-1, NF- $k B$, Fas, AP-1, Bcl-2, Bcl-xL) [45]. The ethanol extracts inhibit angiogenesis and induce mitochondrion-dependent apoptosis through PI3K/Akt and XIAP pathways [47]. The aqueous extracts inhibited HepG2 cell growth and enhanced the anticancer activity of 5-fluorouracil via suppressing CDK2-E2F1 activity [48].

Phytochemistry studies show that it contains components with anticancer activities, including anthraquinones, flavones, hemiterpenes, polyphenols, organic acids and polysaccharides [49], of which ursolic acid (Fig. 1i) and oleanolic acid (Fig. 1j) are two major anticancer compounds [46]. Ursolic acid demonstrated effective in anti-leukemia, which involves diverse biological functions, such as inhibition of cell growth, induction of cell differentiation and apoptosis [50]. The associated mechanisms include inactivation of protein kinase $\mathrm{B}$ (PKB), activation of c-Jun $\mathrm{N}$-terminal kinases (JNK) and extracellular signal-regulated kinase (ERK) pathways, intracellular $\mathrm{Ca}^{2+}$ release, etc. Ursolic acid also exhibits therapeutic potential in the treatment of hormone refractory and androgen-sensitive prostate cancer through induction of cancer cell apoptosis via activation of JNK-induced Bcl-2 phosphorylation and degradation [51]. Methylanthraquinone (Fig. 1k), another active compound from HD, shows multiple anticancer effects on many cancer types. It induced apoptosis in human breast cancer MCF-7 cells by increasing intracellular calcium levels, activating JNK, calpain, and eventually caspases 4, 9, 7 [52]. Methylanthraquinone also caused apoptosis in human leukemic U937 cells by decreasing phospho-ERK1/2 and increasing phospho-p38 MAPKs [53]. Taking together, accumulating evidences indicates the therapeutic potential of HD or its components in treating various cancers.

\section{Rabdosiae rubescentis Herba}

Rabdosiae rubescentis Herba (RRH) is the dried aerial part of genus Rabdosia rubescens (Hemsl.) Hara of the Lamiaceae family. RRH, or Dong Ling Cao in Chinese, which means "ice grass" due to its strong heat-clearing and detoxifying properties, is a well-known HCD herb possessing several biological activities, such as anti-bacteria, anti-parasites, anti-inflammation, and anticancer [54].

The chemical components of RRH are relatively complex, mainly including monoterpenes, sesquiterpene, diterpene and tripenoids. Oridonin (Fig. 11), a tetracyclic terpenoid compound, is the main active component purified from RRH [55]. In recent years, increasing attention has been gained on oridonin due to its remarkable growth inhibition and apoptosis induction activities in cancer cells. In vitro and in vivo studies showed that oridonin induced apoptosis in cells derived from a variety of cancers, including hepatocellular carcinoma, breast cancer, skin cancer, colorectal cancer, gallbladder cancer, gastric cancer, pancreatic cancer and osteoma [56]. Notably, oridonin has less cytotoxicity to normal cells such as fibroblasts and lymphoid cells [56]. Oridonin could arrest cell cycle at the G2/M phase in hepatocarcinoma HepG2 cells by upregulating serine-threonine kinase receptor-associated protein, heat shock $70 \mathrm{kDa}$ protein 1 , stress-induced phosphoprotein 1, etc. [57]. Oridonin also drastically suppresses tumor invasion and metastasis in vitro via regulating the integrin $\beta 1 / F A K$ pathway and decreasing the expression of MMPs in MDA-MB-231 cells in vitro [58]. A study on cervical cancer found that 
oridonin induced the apoptosis of cancer cells through PI3K/Akt pathway [59]. In another study on gastric cancer indicated that the mechanism of oridonin-induced apoptosis involved Apaf-1, cytochrome c and caspase-3 signaling pathway [60]. Accumulating studies have shown an enhanced anticancer effect when oridonin was combined with imatinib in $\mathrm{Ph}^{+}$acute lymphoblastic leukemia cells. The results showed that oridonin inhibited the activations of LYN (one of SRC family kinases) and ABL and their downstream Raf/MEK/ERK, Akt/mTOR, and STAT5 pathways, decreased $\mathrm{Bcl}-2 / \mathrm{Bax}$ ratio and then induced apoptosis in $\mathrm{Ph}^{+}$ALL cells [61]. In addition, some recent studies suggested that oridonin could also inhibit the proliferation of tumor cells by increasing the autophagy of tumor cells [62]. Current research on pancreatic cancer cells indicated that oridonin could induce apoptosis via p53- and caspase-dependent induction of p38 MAPK [63]. Meanwhile, apoptosis, autophagy and loss of the mitochondrial transmembrane potential have been observed in lung cancer cell line A549 treated with oridonin [64]. Therefore, oridonin is supposed to be a promising compound for chemotherapy.

\section{Scutellariae barbatae Herba}

Scutellariae barbatae Herba (SBH) is the dried whole plant of genus Scutellaria barbata D. Don of the Lamiaceae family. SBH contains several flavonoids, alkaloids, polysaccharides, and steroids [65]. The extracts of SBH exhibited significant anticancer activities in several human cancers such as colon cancer, leukemia, hepatoma, skin cancer, breast cancer and chorioepithelioma [66]. Despite the distinguished success of this herb in treating cancer, the precise molecular mechanisms still remain to be investigated. Studies revealed that ethanol extract of SBH (ESBH) could induce apoptosis, inhibit proliferation and angiogenesis in colon cancer [67]. Administration of ESBH remarkably increased the levels of pro-apoptotic $\mathrm{Bax} / \mathrm{Bcl}-2$ ratio and the expression of suppressor gene p21, whereas decreased the expression of pro-proliferative genes Cyclin D1 and CDK4 [67]. Further studies on benign smooth muscle cell tumor model demonstrated that SBH could induce differentiation and apoptosis in uterine smooth muscle cells [68]. In addition, SBH showed well-validated chemopreventive activity at stages of initiation, promotion, and progression of cancer [69]. Increasing evidences have also revealed that the combination therapy of SBH with other commonly prescribed chemotherapeutic agents could considerably inhibit the growth of carcinoma both in vitro and in vivo [70]. Although the active anticancer constituents have not been identified, flavonoids in SBH have become the focus of researches, since this kind of compounds strongly inhibited cancer cell proliferation, induced mitochondria-dependent apoptosis, and inhibited tumor angiogenesis [65]. Nevertheless, more efforts are required to investigate the active compounds in SBH to facilitate the research and development of this promising anticancer herb.

\section{Summary of the major active compounds and their actions} The chemical structures of major anticancer compounds in the representative HCD herbs are shown in Fig. 1. The anticancer activities and their mechanisms of the major compounds in the above-discussed and other typical HCD herbs are summarized in Table 1. The anticancer compounds in HCD herbs are comprised of various types of chemicals, including, but not limiting to, alkaloids (e.g. berberine, matrine and colchicine), flavonoids (e.g. baicalein, wogonin, luteolin, apigenin and tectorigenin), terpenoids (e.g. oridonin, ursolic acid, oleanolic acid, artemisinin and saikogenin), anthraquinones, polyphenols, organic acids (e.g. ursolic acid and oleanolic acid), polysaccharides, saponins (e.g. saikosaponin and pulsatilla saponins), etc. Studies indicated that the active compounds from HCD herbs exhibited multifarious anticancer activities, such as inhibition of proliferation, invasion, metastasis, inflammation, and angiogenesis, induction of differentiation, apoptosis and cell cycle arrest, antioxidation, and modulation of immune function (Fig. 2). The versatile anticancer effects of these compounds are also indicated by the potency against a broad spectrum of cancer types, both various solid tumors and hematopoietic malignancies. HCD herbs are primarily characterized by the heat-clearing and detoxicating properties in TCM theory, which correlate with their antioxidant activity. Indeed, most, if not all, compounds from HCD herbs are antioxidants, such as berberine, matrine, baicalein, polyphenols and polysaccharides. Since tumors frequently exhibit high levels of oxidative stress [71], a general disturbance of redox balance in cancer cells by HCD herbal compounds may contribute to their multifarious anticancer effects. In addition, these compounds could regulate a wide range of signaling pathways, kinase activity and gene expression, which are involved in cell proliferation, cell cycle, apoptosis, invasion, metastasis, etc. However, the anticancer potential and detailed molecular mechanisms of the compounds remain to be further elucidated.

\section{The representative anticancer formulas containing HCD herbs}

Cocktails of medicines are usually applied to treat complex syndromes or diseases, like cancers and cardiovascular diseases. Similarly, single herb is seldom used in TCM, of which formulas with combination of various herbs are much more often prescribed on the basis of individual conditions according to TCM theory. Cancers often exhibit excessive heat and toxin. Therefore, one or more HCD herbs are the major components in anticancer TCM formulas. In recent 
Chang et al. Chin Med (2017) 12:20

Page 7 of 15

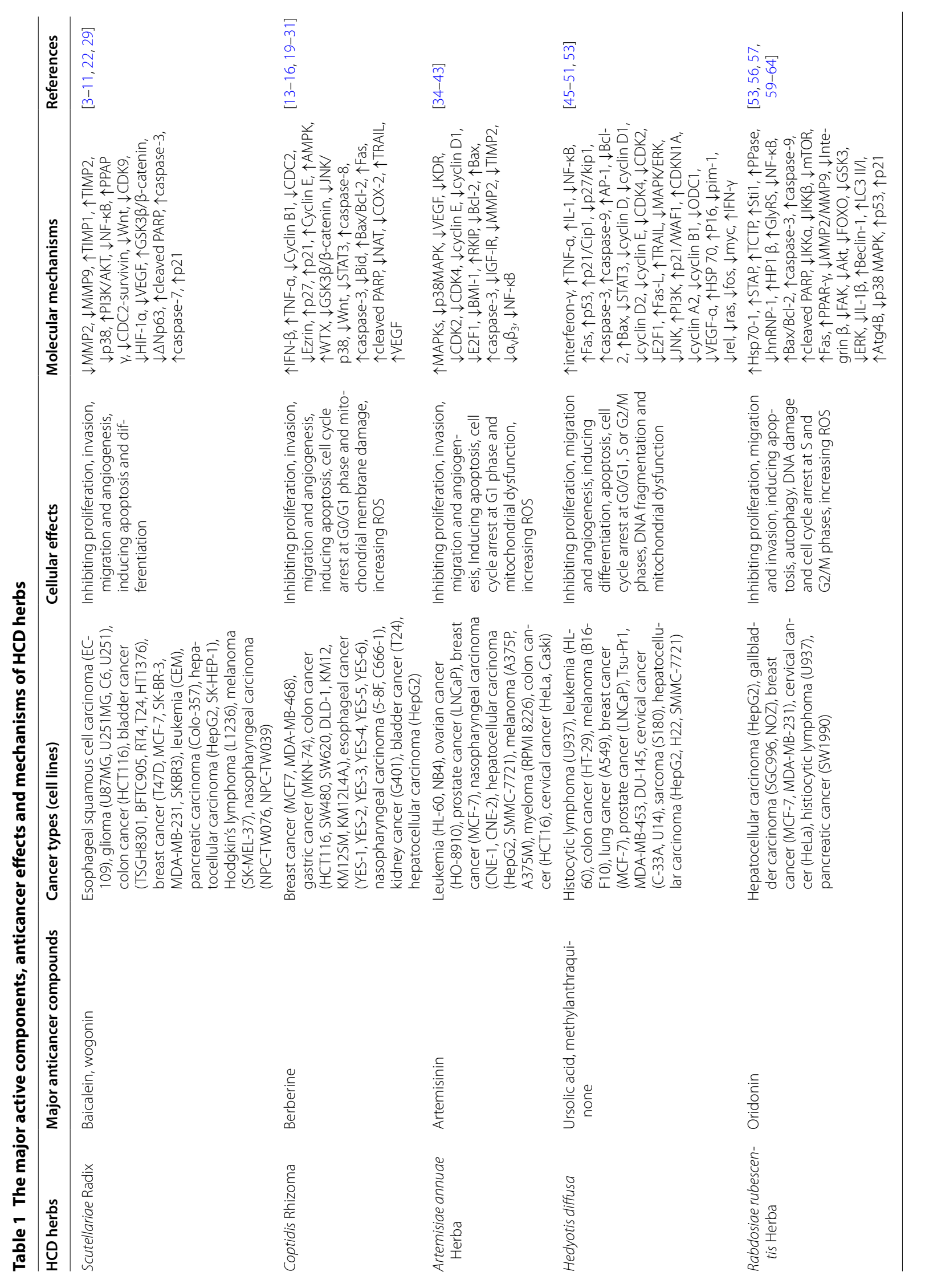




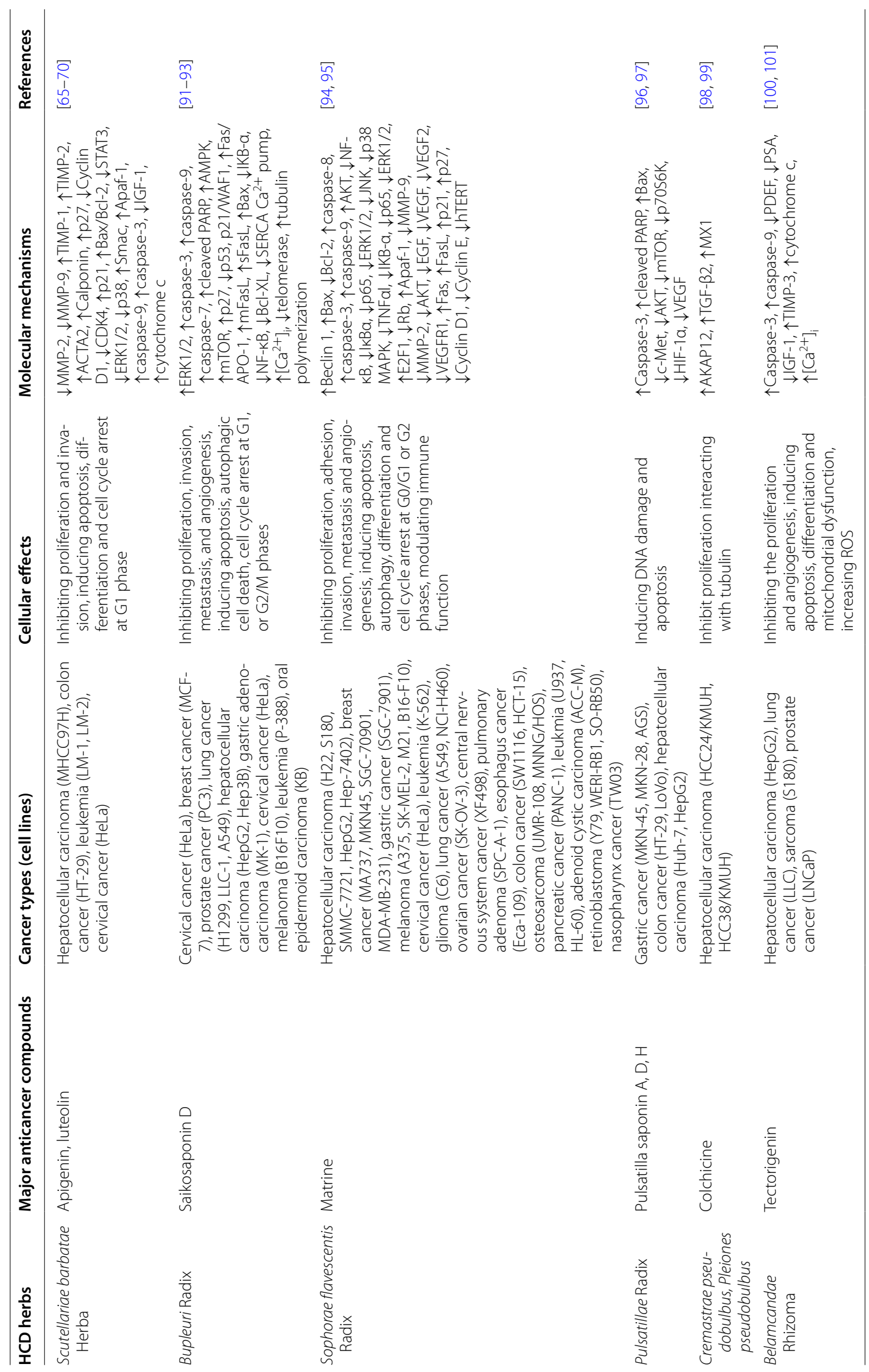




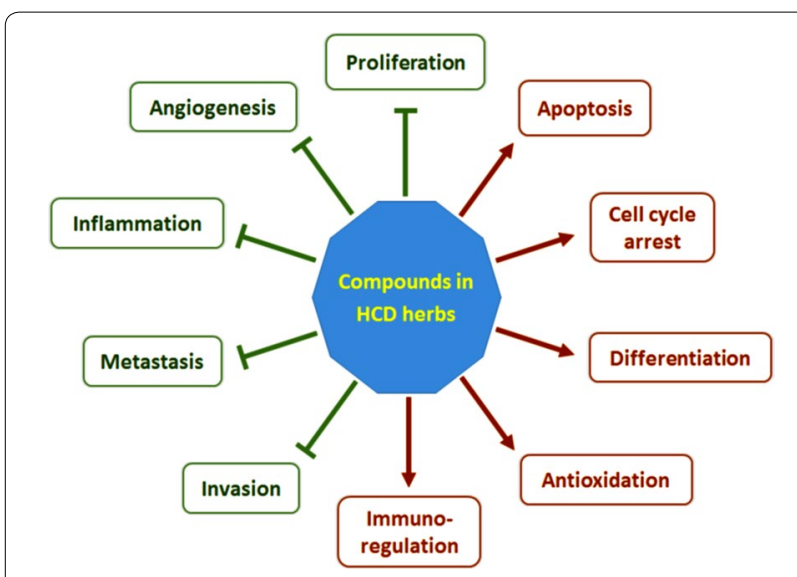

Fig. 2 Schematic diagram showing the anticancer activities and mechanisms of compounds in HCD herbs

years, the application of TCM prescriptions in the treatment of various malignant tumors has obtained encouraging outcomes, at least partially owing to that multiple components can act on multiple targets and exert synergistic therapeutic efficacies. In particular, apart from traditional decoction and oral administration methods, advanced pharmaceutical technologies are used in TCM formula preparations with distinctive advantages and features, including tablets, pills, capsules, injections, powder, liquids, etc. [72]. The following representative anticancer formulas containing HCD herbs are discussed in details, including Yanshu Injection, Huanglian Jiedu Tang, Jiedu Xiaozheng Yin and PHY906. Some others are listed in Table 2.

\section{Yanshu Injection}

Yanshu Injection (YSI), also named Fu Fang Ku Shen injection, consists of two herbs: Sophorae flavescentis Radix (SFR, or Ku Shen) and Smilacis glabrae Rhizoma (SGR, or Tu Fu Ling) with the ratio of 7 to 3. Both of them belong to heat-clearing and detoxifying herbs. SFR is commonly used for the treatment of viral hepatitis, cancer, enteritis, viral myocarditis, arrhythmia, skin diseases, etc. The major anticancer compounds in SFR are oxymatrine (Fig. 1p) and matrine (Fig. 1q), which have been approved for the treatment of cancers by the Chinese State Food and Drug Administration (SFDA) [73]. The compounds showed broad spectrum of anticancer activities including stomach, esophagus, liver, colon, lung, cervix, ovary, and breast cancers, through multiple mechanisms, such as inhibiting cancer cell proliferation, inducing apoptosis and autophagy, modulating immune response, reducing cancer cell adhesion, invasion and migration [73]. SGR is widely used both in food supplementary and health care, owing to its properties of heat-clearing and detoxication. Studies reported its therapeutic potential for the treatment of rheumatoid arthritis, inflammation, liver injury, hyperinsulinemia and cancer [74]. Crude extraction of SGR as well as its pure compounds including astilbin, 5-O-caffeoylshikimic acid and taxifolin, could promote cancer cell apoptosis and block cancer cell adhesion, invasion and migration by inhibiting transforming growth factor beta 1 (TGF- $\beta 1$ ) signaling pathway. YSI was reported to be able to directly inhibit gastric cancer cell proliferation and block the experimental gastric carcinogenesis by preventing carcinogen-induced oxidative damage and improving immune function [75]. However, YSI was mostly applied in combination with chemotherapy or radiotherapy in cancer treatment. Studies showed that YSI plus transcatheter arterial chemoembolization (TACE) could synergistically enhance the therapeutic effects of TACE, alleviate the adverse responses of radiotherapy and chemotherapy, improve the patients' life quality, and reduce the cancer recurrence [76].

\section{Huanglian Jiedu Tang}

Huanglian Jiedu Tang (HJT), a classic herbal formula, consists of four herbs: Coptis Rhizome (Huang Lian), Phellodendri chinensis Cortex (Huang Bai), Scutellariae Radix (Huang Qin), and Gardeniae Fructus (Zhi $\mathrm{Zi}$ ), with equal proportion. In this prescription, the first three herbs listed above have the roles of purging fire and removing toxin, and function as monarch, minister and assistant in the formula, respectively. The decoction, previously acting as an anti-inflammatory agent, is widely used for treating dermatitis, gastritis, liver injuries, and bleeding of the intestines and uterus [77]. HJT has been extensively used in TCM practice even though their mechanisms of action remain unclear. It was reported that HJT could effectively cause hepatoma cell cycle arrest by upregulating the inactive form of $\mathrm{Cdc} 2$ and $\mathrm{Cdc} 25$, and downregulating the levels of $\mathrm{Bcl}-2$ and Bcl-xL. Moreover, HJT exerted antitumor effect through increasing the expression of Bax and Bak and decreasing the expression of $\mathrm{Bcl}-2$ and $\mathrm{Bcl}-\mathrm{xL}$ via inhibition of the NF- $\mathrm{kB}$ activity, and consequently inducing the mitochondria-dependent apoptosis in hepatoma cells [78]. HJT could inhibit primary myeloma cell proliferation and survival, and induce the cell apoptosis via a mitochondria-mediated pathway. Further studies revealed that Scutellaria Radix and one of its major compounds baicalein were responsible for the anticancer effect of HJT on myeloma [79]. Experiments were conducted on evaluating the preventive effect of oral administration of HJT on stomatitis and diarrhea induced by cytotoxic drugs in patients with acute leukemia. It was found that the incidence of mucositis and diarrhea was apparently lower than the control group [80]. In addition, 


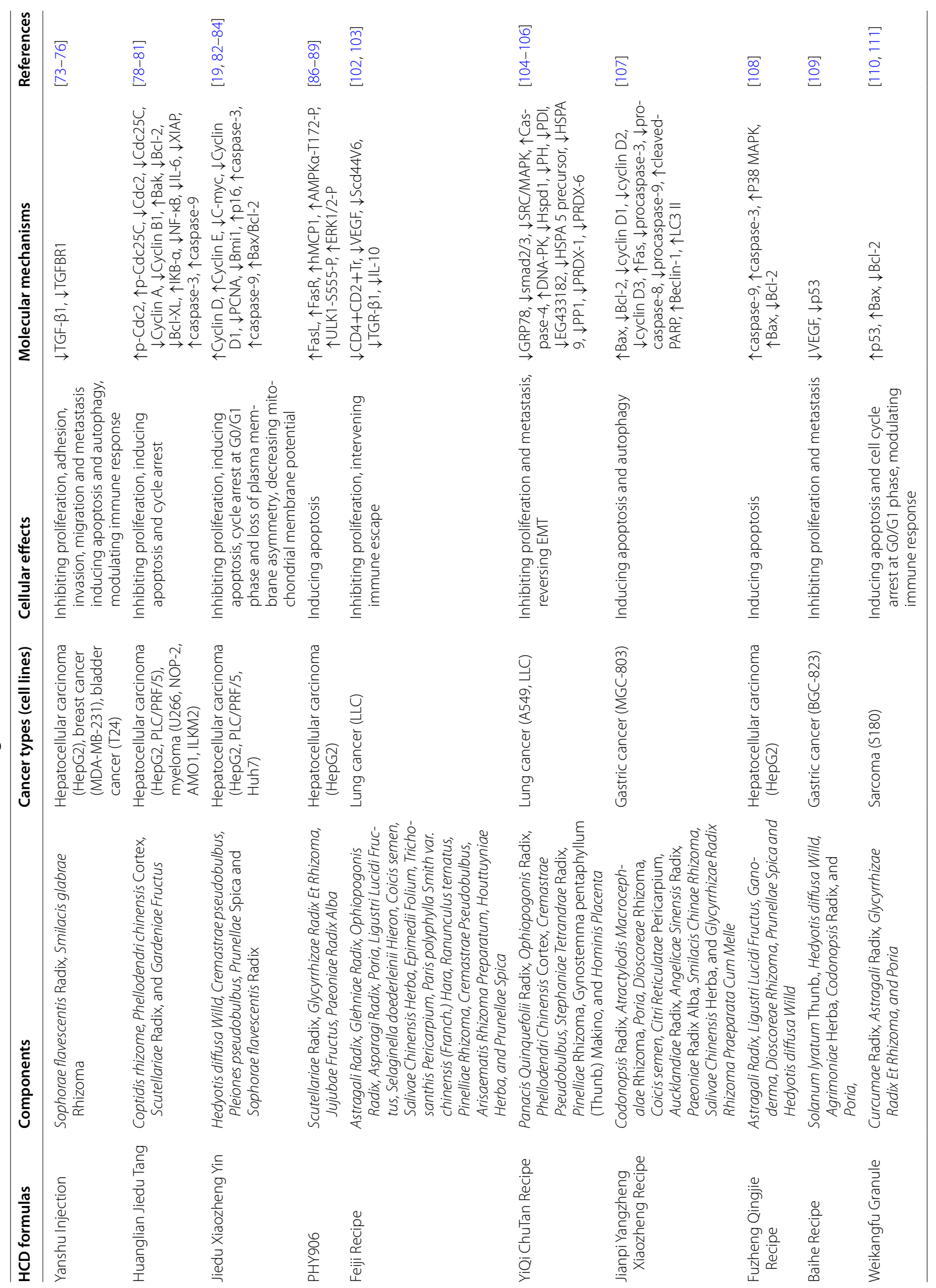


HJT shows remarkable chemopreventive effect with low toxicity on colon cancer by inhibiting COX-2, which is involved in the production of prostanoids that could promote inflammation and tumorigenesis, but not COX-1, a constitutively expressed enzyme for normal functions of many organs [81], indicating the advantages of HJT over non-steroidal anti-inflammatory drugs, which inhibit both COX-1 and COX-2.

\section{Jiedu Xiaozheng Yin}

Jiedu Xiaozheng Yin (JXY), an anticancer decoction of TCM possessing heat-clearing and detoxification properties, consists of Hedyotis diffusa (Bai Hua She She Cao), Cremastrae pseudobulbus Pleiones pseudobulbus (Shan $\mathrm{Ci} \mathrm{Gu}$ ), Prunellae Spica (Xia Ku Cao) and Sophorae flavescentis Radix (Ku Shen). The formula exerted growth inhibitory effect on HepG2 hepatocarcinoma cells in a dose-dependent manner via increasing the expression of G1-related cyclins D and E [82]. However, the constituents that responsible for the antitumor effects are still largely unknown. In vitro experiments indicated that JXY inhibited the proliferation of gastric carcinoma cell line and promoted apoptosis via mitochondrial pathway in the hepatic carcinoma cancer cells. The ethanol extract of JXY (EE-JXY) decreases the viability of human umbilical vein endothelial cells and the tube formation capacity. Moreover, EE-JXY inhibits angiogenesis in chick chorioallantoic membrane and decreases microvessel density in the xenograft tumor. Further results demonstrated that JXY inhibited angiogenesis by downregulating VEGF-A and VEGFR-2 expression [19]. Recent studies reported that ethyl acetate extraction of JXY significantly inhibited hepatoma cell growth both in vitro and in the mouse xenograft model through arresting cancer cells at G0/ G1 phase, inhibiting angiogenesis, and inducing cancer cell apoptosis, which may involve the suppression of the Bmil and Wnt/ $\beta$-catenin signaling pathways [83]. A clinical study was conducted on hepatic carcinoma in III stage patients treated with JXY for 7 days before operation and Fuzheng Yiliu recipe after operation for 2 years. The results demonstrated that administration of compound Chinese herbal medicines in peri-operational period significantly decreased the recurrence rate, improved patients' immune function and increased the cumulative survival rate [84].

\section{PHY906}

PHY906, derived from a famous TCM formula called Huang Qin Tang, is composed of four herbs: Scutellariae Radix (Huang Qin), Glycyrrhizae Radix Et Rhizoma (Gan Cao), Jujubae Fructus (Da Zao), and Paeoniae Radix Alba (Shao Yao), with a ratio of 3:2:2:2. Huang Qin Tang has been used for more than 1000 years in TCM in treating various gastrointestinal discomfort, such as abdominal cramps, vomiting, diarrhea and nausea [85]. Although PHY906 alone has little antitumor effect, it was developed to be an effective TCM recipe for the relief of gastrointestinal toxicity and improvement of the antitumor efficacy of chemotherapeutic drugs, which has been proven both in preclinical animal models and in clinical studies. In a phase I clinical study, it was found that PHY906 could increase the therapeutic outcomes of capecitabine by reducing side effects such as diarrhea in patients with advanced pancreatic cancer, colon cancer, cholangiocarcinoma, or esophageal cancer [86]. In a phase II study, combination administration of PHY906 and capecitabine for patients with advanced pancreatic cancer resulted in a well tolerate and response of the treatment and improved indices of quality of life, including fatigue, loss of appetite, nausea, impaired sense of well-being, and diarrhea [87]. Studies revealed that PHY906 possessed a wide range of pharmacological activities due to its multiple components and mechanisms, including inhibitory activities on multi-drug resistant protein (MDR) and CYP450 which could result in enhancement of cellular uptake of chemotherapeutic agents, inhibitory activities on NF- $\mathrm{kB}$ and matrix metalloproteases which could inhibit angiogenesis and enhance the antitumor effect of chemotherapeutic agents, and inhibition of tachykinin NK-1, opiate $\delta$ receptors and acetylcholine esterase which may contribute to the improvement of quality of life [88]. Although PHY906 does not directly protect the initial impairment of intestine caused by irinotecan, it can effectively ameliorate inflammatory responses through inhibiting multiple inflammation related targets, including TNF$\alpha$-induced NF- $\mathrm{kB}$-mediated transcriptional activity and COX-2 and iNOS enzyme activity. In addition, PHY906 remarkably promotes the recovery of damaged intestinal mucosa by increasing the proliferation of progenitor or stem cells and the growth of the crypts through potentiating Wnt/ $\beta$-catenin signaling activity [89]. This suggests that herbal medicines with multiple components and molecular targets could be promising in future drug discovery and development for the potential management of complicated diseases.

\section{Conclusions and perspectives}

Organisms, at either cellular, organ, or organismal levels, are complex systems featuring redundant networks, selforganization and adaptation to the environment. Similarly, malignant cancers evolve to be a complex system with highly genetic diversity and enormous capability of adaptation to selective pressure [90]. Chinese medicinal herbs and the person-based formulas contain hundreds even thousands of compounds, which may regulate the activities or expression of a broad spectrum of proteins. 
In this regard, Chinese herbal medicine might be a promising approach for the management of multifactorial chronic diseases including cancers. Since the accumulation of heat and toxins plays a key role in the occurrence and development of cancers according to TCM theory, HCD herbs are commonly prescribed in TCM formulas for the treatment of cancer. Increasing evidences have shown that decoction or components of HCD herbs or HCD herbs-containing formulas exhibited favorable anticancer effects directly or through enhancing the activities of chemotherapeutic drugs. However, huge efforts still need to be deployed in this field to bring the most potentials of HCD herbs for cancer treatment, including (1) further evaluation of anticancer efficacy of HCD herbs and formulas, particularly using xenograft animal tumor models; (2) further identification of major component(s) in HCD herbs responsible for the anticancer activity since many of them still have not been identified; (3) investigation of the underlying molecular mechanisms for the anticancer effects of HCD herbs and formulas, particular using cutting-edge technologies for complex sample analysis, e.g. proteomics and metabolomics approaches, since herbs or formulas may have complex mechanisms of action; (4) studies on the adjuvant anticancer activity of HCD herbs and formulas, e.g. sensitizing cancer cells to chemo- or radiotherapy, reversing multidrug resistance, reducing chemotherapy side effects, etc.; (5) studies on the acute and chronic toxicity of HCD herbs extracts and the purified components are also highly demanded. In summary, HCD herbs, formulas and the purified components have highly potential to be developed as anticancer agents used alone or in combination with other therapeutic methods.

\footnotetext{
Abbreviations

AATG4B: autophagy related 4 homolog B; ACTA2: smooth muscle alpha (a)-2 actin; AKAP12: A-kinase anchor protein 12; AMPK: AMP-activated protein kinase; AP-1: activator protein 1; $\left[\mathrm{Ca}^{2+}\right]$; intracellular calcium; CCNA2: cyclin A2; CDC: cyclin-dependent kinases; COX-2: cyclooxygenase 2; CREB: CAMP response element-binding protein; DNA-PK: DNA-dependent protein kinase; ERK: extracellular signal-regulated kinases; FAK: focal adhesion kinase; FasL: Fas ligand; FOXO: forkhead box O proteins; GlyRS: glycyl-tRNA synthetase; GRP78: glucose-regulated protein 78; GSK3 $\beta$ : glycogen synthase kinase $3 \beta$; HCD: heatclearing and detoxicating; HIF-1a: hypoxia-inducible factor 1a; hMCP1: human monocyte chemoattractant protein-1; hnRNP-1: heterogeneous nuclear ribonucleoprotein 1; HP1: heterochromatin protein 1; HSP 70: heat shock protein 70; hTERT: human telomerase reverse transcriptase; IFN: interferons; IGF-1: insulin-like growth factor 1; IGF-IR: type 1 IGF receptor; IKB: IKB; IKK: IKB kinases; IL-1 $\beta$ : interleukin $1 \beta$; JNK: $c$-Jun N-terminal kinases; KDR: kinase insert domain receptor; LC3: microtubule-associated protein 1A/1B-light chain 3; MAPK: mitogen-activated protein kinases; mFasL: membrane-bound FasL; MMP: matrix metalloproteinases; mTOR: mechanistic target of rapamycin protein; MX1: an interferon-induced GTP-binding protein; NAT: N-acyltransferases; NFKB: nuclear factor-KB; ODC1: ornithine decarboxylase 1; p70S6K: p70S6 kinase; PARP: poly (ADP-ribose) polymerase; p-Cdc: phosphorylated CDC; PCNA: proliferating cell nuclear antigen; PDEF: prostate-derived Ets transcription factor; PDI: protein disulfide isomerase; PI3K: phosphoinositide 3-kinase; PP1: protein phosphatase 1; PPAR $\gamma$ : peroxisome proliferator-activated receptor $\gamma$; PPase:
}

protein Phosphatase; PRDX: peroxiredoxins; PSA: prostate-specific antigen; Rb: retinoblastoma protein; RKIP: Raf kinase inhibitor protein; sFasL: soluble form of FasL; STAP: stellate cell activation-associated protein; STAT3: signal transducer and activator of transcription 3; TCM: traditional Chinese medicine; TCTP: translationally controlled tumor protein; TGFBR1: transforming growth factor $\beta$ receptor 1;TIMP: metallopeptidase inhibitors; TNF-a: tumor necrosis factor a; TRAIL: TNF-related apoptosis-inducing ligand; ULK1: Unc-51 like autophagy activating kinase 1;VEGF: vascular endothelial growth factor; WTX: Wilms tumor gene on X chromosome; XIAP: X-linked inhibitor of apoptosis protein.

\section{Authors' contributions}

CH supervised the study. YZ, YL and CH collected and analyzed the data and wrote the paper. All authors read and approved the final manuscript.

\section{Acknowledgements}

Not applicable.

\section{Competing interests}

The authors declare that they have no competing interests.

\section{Availability of data and materials}

All data generated or analyzed during this study are included in this published article.

\section{Funding}

Macao Science and Technology Development Fund (041/2016/A), the Research Fund of the University of Macau (MYRG107(Y1-L3)-ICMS13-HCW and MYRG2015-00081-ICMS-QRCM).

\section{Publisher's Note}

Springer Nature remains neutral with regard to jurisdictional claims in published maps and institutional affiliations.

Received: 30 March 2017 Accepted: 30 June 2017

Published online: 12 July 2017

References

1. Zhang ZN, Lv JR, Lei XM, Li SY, Zhang Y, Meng LH, Xue RL, Li ZF. Baicalein reduces the invasion of glioma cells via reducing the activity of p38 signaling pathway. PLOS ONE. 2014;9(2):e90318.

2. Zhang HB, Lu P, Guo QY, Zhang ZH, Meng XY. Baicalein induces apoptosis in esophageal squamous cell carcinoma cells through modulation of the PI3K/Akt pathway. Oncol Lett. 2013:5(2):722-8.

3. Ma GZ, Liu CH, Wei B, Qiao J, Lu T, Wei HC, Chen HD, He CD. Baicalein inhibits DMBA/TPA-induced skin tumorigenesis in mice by modulating proliferation, apoptosis, and inflammation. Inflammation. 2013;36(2):457-67.

4. Kim DH, Hossain MA, Kang YJ, Jang JY, Lee YJ, Im E, Yoon JH, Kim HS, Chung HY, Kim ND. Baicalein, an active component of Scutellaria baicalensis Georgi, induces apoptosis in human colon cancer cells and prevents AOM/DSS-induced colon cancer in mice. Int J Oncol. 2013:43(5):1652-8.

5. Chao Jl, Su WC, Liu HF. Baicalein induces cancer cell death and proliferation retardation by the inhibition of CDC2 kinase and survivin associated with opposite role of p38 mitogen-activated protein kinase and AKT. Mol Cancer Ther. 2007;6(11):3039-48.

6. Polier G, Ding J, Konkimalla BV, Eick D, Ribeiro N, Kohler R, Giaisi M, Efferth T, Desaubry L, Krammer PH, et al. Wogonin and related natural flavones are inhibitors of CDK9 that induce apoptosis in cancer cells by transcriptional suppression of Mcl-1. Cell Death Dis. 2011;2:e182.

7. Chow SE, Chang YL, Chuang SF, Wang JS. Wogonin induced apoptosis in human nasopharyngeal carcinoma cells by targeting GSK-3beta and DeltaNp63. Cancer Chemother Pharmacol. 2011;68(4):835-45.

8. Song X, Yao J, Wang F, Zhou M, Zhou Y, Wang H, Wei L, Zhao L, Li Z, Lu $\mathrm{N}$, et al. Wogonin inhibits tumor angiogenesis via degradation of HIF1alpha protein. Toxicol Appl Pharmacol. 2013;271(2):144-55. 
9. Zhong Y, Zhang FY, Sun ZY, Zhou W, Li ZY, You QD, Guo QL, Hu R. Drug resistance associates with activation of Nrf2 in MCF-7/DOX cells, and wogonin reverses it by down-regulating NRF2-mediated cellular defense response. Mol Carcinog. 2013;52(10):824-34.

10. Lee E, Enomoto R, Koshiba C, Hirano H. Inhibition of P-glycoprotein by wogonin is involved with the potentiation of etoposide-induced apoptosis in cancer cells. Ann N Y Acad Sci. 2009;1171:132-6.

11. Zhao Q, Wang J, Zou MJ, Hu R, Zhao L, Qiang L, Rong JJ, You QD, Guo QL. Wogonin potentiates the antitumor effects of low dose 5 -fluorouracil against gastric cancer through induction of apoptosis by downregulation of NF-kB and regulation of its metabolism. Toxicol Lett. 2010;197(3):201-10.

12. He C, Rong R, Liu J, Wan J, Zhou K, Kang JX. Effects of Coptis extract combined with chemotherapeutic agents on ROS production, multidrug resistance, and cell growth in A549 human lung cancer cells. Chin Med. 2012;7(1):11.

13. Kang JX, Liu J, Wang J, He C, Li FP. The extract of huanglian, a medicinal herb, induces cell growth arrest and apoptosis by upregulation of interferon- $\beta$ and TNF- $\alpha$ in human breast cancer cells. Carcinogenesis. 2005;26(11):1934-9.

14. Liu J, He C, Zhou K, Wang J, Kang JX. Coptis extracts enhance the anticancer effect of estrogen receptor antagonists on human breast cancer cells. Biochem Biophys Res Commun. 2009;378(2):174-8.

15. Li XK, Motwani M, Tong W, Bornmann W, Schwartz GK. Huanglian, a Chinese herbal extract, inhibits cell growth by suppressing the expression of cyclin B1 and inhibiting CDC2 kinase activity in human cancer cells. Mol Pharmacol. 2000;58(6):1287-93.

16. lizuka N, Miyamoto K, Okita K, Tangoku A, Hayashi H, Yosino S, Abe T, Morioka T, Hazama S, Oka M. Inhibitory effect of Coptidis rhizoma and berberine on the proliferation of human esophageal cancer cell lines. Cancer Lett. 2000;148(1):19-25.

17. lizuka N, Hazama S, Yoshimura K, Yoshino S, Tangoku A, Miyamoto K, Okita K, Oka M. Anticachectic effects of the natural herb Coptidis rhizoma and berberine on mice bearing colon 26/clone 20 adenocarcinoma. Int J Cancer. 2002;99(2):286-91.

18. Ong ES, Woo SO, Yong YL. Pressurized liquid extraction of berberine and aristolochic acids in medicinal plants. Chromatogr A. 2000;904(1):57-64.

19. Tang J, Feng Y, Tsao S, Wang N, Curtain R, Wang Y. Berberine and Coptidis rhizoma as novel antineoplastic agents: a review of traditional use and biomedical investigations. J Ethnopharmacol. 2009;126(1):5-17.

20. Marverti G, Ligabue A, Lombardi P, Ferrari S, Monti MG, Frassineti C, Costi MP. Modulation of the expression of folate cycle enzymes and polyamine metabolism by berberine in cisplatin-sensitive and -resistant human ovarian cancer cells. Int J Oncol. 2013:43(4):1269-80.

21. Liu X, Ji Q, Ye NJ, Sui H, Zhou LH, Zhu HR, Fan ZZ, Cai JF, Li Q. Berberine inhibits invasion and metastasis of colorectal cancer cells via COX-2/PGE(2) mediated JAK2/STAT3 signaling pathway. PLOS ONE. 2015;10(5):e0123478.

22. Zhang J, Cao H, Zhang B, Xu X, Ruan H, Yi T, Tan L, Qu R, Song G, Wang B, et al. Berberine potently attenuates intestinal polyps growth in ApcMin mice and familial adenomatous polyposis patients through inhibition of Wnt signalling. J Cell Mol Med. 2013;17(11):1484-93.

23. Tsang CM, Cheung YC, Lui VW, Yip YL, Zhang G, Lin VW, Cheung KC, Feng Y, Tsao SW. Berberine suppresses tumorigenicity and growth of nasopharyngeal carcinoma cells by inhibiting STAT3 activation induced by tumor associated fibroblasts. BMC Cancer. 2013;13:619.

24. Zhu T, Li LL, Xiao GF, Luo QZ, Liu QZ, Yao KT, Xiao GH. Berberine increases doxorubicin sensitivity by suppressing STAT3 in lung cancer. Am J Chin Med. 2015;43(7):1487-502.

25. Hwang JM, Kuo HC, Tseng TH, Liu JY, Chu CY. Berberine induces apoptosis through a mitochondria/caspases pathway in human hepatoma cells. Arch Toxicol. 2006;80(2):62-73.

26. Patil JB, Kim J, Jayaprakasha GK. Berberine induces apoptosis in breast cancer cells (MCF-7) through mitochondrial-dependent pathway. Eur J Pharmacol. 2010;645(1-3):70-8.

27. Fan LX, Liu CM, Gao AH, Zhou YB, Li J. Berberine combined with 2-deoxy-D-glucose synergistically enhances cancer cell proliferation inhibition via energy depletion and unfolded protein response disruption. Biochim Biophys Acta. 2013;1830(11):5175-83.
28. Hur JM, Hyun MS, Lim SY, Lee WY, Kim D. The combination of berberine and irradiation enhances anti-cancer effects via activation of p38 MAPK pathway and ROS generation in human hepatoma cells. J Cell Biochem. 2009;107(5):955-64.

29. Zhang C, Yang X, Zhang Q, Yang B, Xu L, Qin Q, Zhu H, Liu J, Cai J, Tao $\mathrm{G}$, et al. Berberine radiosensitizes human nasopharyngeal carcinoma by suppressing hypoxia-inducible factor-1alpha expression. Acta OtoLaryngol. 2014;134(2):185-92.

30. Yu M, Tong X, Qi B, Qu H, Dong S, Yu B, Zhang N, Tang N, Wang L, Zhang C. Berberine enhances chemosensitivity to irinotecan in colon cancer via inhibition of NFkB. Mol Med Rep. 2014;9(1):249-54.

31. Tillhon M, Ortiz LMG, Lombardi P, Scovassi Al. Berberine: new perspectives for old remedies. Biochem Pharmacol. 2012;84(10):1260-7.

32. van der Kooy F, Sullivan SE. The complexity of medicinal plants: the traditional Artemisia annua formulation, current status and future perspectives. J Ethnopharmacol. 2013;150(1):1-13.

33. Ho WE, Peh HY, Chan TK, Wong WS. Artemisinins: pharmacological actions beyond anti-malarial. Pharmacol Ther. 2014;142(1):126-39.

34. Efferth T, Sauerbrey A, Olbrich A, Gebhart E, Rauch P, Weber HO, Hengstler JG, Halatsch ME, Volm M, Tew KD, et al. Molecular modes of action of artesunate in tumor cell lines. Mol Pharmacol. 2003;64(2):382-94.

35. Chen HH, Zhou HJ, Wu GD, Lou XE. Inhibitory effects of artesunate on angiogenesis and on expressions of vascular endothelial growth factor and VEGF receptor KDR/flk-1. Pharmacology. 2004;71(1):1-9.

36. Tin AS, Sundar SN, Tran KQ, Park AH, Poindexter KM, Firestone GL. Antiproliferative effects of artemisinin on human breast cancer cells requires the downregulated expression of the E2F1 transcription factor and loss of E2F1-target cell cycle genes. Anticancer Drugs. 2012;23(4):370-9.

37. Hu CJ, Zhou L, Cai Y. Dihydroartemisinin induces apoptosis of cervical cancer cells via upregulation of RKIP and downregulation of bcl-2. Cancer Biol Ther. 2014;15(3):279-88.

38. Dong HY, Wang ZF. Antitumor effects of artesunate on human breast carcinoma MCF-7 cells and IGF-IR expression in nude mice xenografts. Chin J Cancer Res. 2014;26(2):200-7.

39. Riganti C, Doublier S, Viarisio D, Miraglia E, Pescarmona G, Ghigo D, Bosia A. Artemisinin induces doxorubicin resistance in human colon cancer cells via calcium-dependent activation of HIF-1alpha and P-glycoprotein overexpression. Br J Pharmacol. 2009;156(7):1054-66.

40. Weifeng T, Feng S, Xiangji L, Changqing S, Zhiquan Q, Huazhong Z, Peining $Y$, Yong $Y$, Mengchao W, Xiaoqing J, et al. Artemisinin inhibits in vitro and in vivo invasion and metastasis of human hepatocellular carcinoma cells. Phytomedicine. 2011;18(2-3):158-62.

41. Hu W, Chen SS, Zhang JL, Lou XE, Zhou HJ. Dihydroartemisinin induces autophagy by suppressing NF-kB activation. Cancer Lett. 2014;343(2):239-48.

42. Chen T, Li M, Zhang R, Wang H. Dihydroartemisinin induces apoptosis and sensitizes human ovarian cancer cells to carboplatin therapy. J Cell Mol Med. 2009;13(7):1358-70.

43. Zhao C, Gao W, Chen T. Synergistic induction of apoptosis in A549 cells by dihydroartemisinin and gemcitabine. Apoptosis. 2014;19(4):668-81.

44. Ishigami Sl, Arii S, Furutani M, Niwano M, Harada T, Mizumoto M, Mori A, Onodera H, Imamura M. Predictive value of vascular endothelial growth factor (VEGF) in metastasis and prognosis of human colorectal cancer. Br J Cancer. 1998;78(10):1379-84.

45. Niu Y, Meng QX. Chemical and preclinical studies on Hedyotis diffusa with anticancer potential. J Asian Nat Prod Res. 2013;15(5):550-65.

46. Lee HZ, Bau DT, Kuo CL, Tsai RY, Chen YC, Chang YH. Clarification of the phenotypic characteristics and anti-tumor activity of Hedyotis diffusa. Am J Chin Med. 2011:39(1):201-13.

47. Lin JM, Chen YQ, Wei LH, Chen XZ, Xu W, Hong ZF, Sferra TJ, Peng J. Hedyotis diffusa Willd extract induces apoptosis via activation of the mitochondrion-dependent pathway in human colon carcinoma cells. Int J Oncol. 2010;37(5):1331-8.

48. Chen XZ, Cao ZY, Chen TS, Zhang YQ, Liu ZZ, Su YT, Liao LM, Du J. Water extract of Hedyotis diffusa Willd suppresses proliferation of human HepG2 cells and potentiates the anticancer efficacy of lowdose 5-fluorouracil by inhibiting the CDK2-E2F1 pathway. Oncol Rep. 2012;28(2):742-8. 
49. Wang X, Cheng WM, Yao XN, Guo XJ. Qualitative analysis of the chemical constituents in Hedyotis diffusa by HPLC-TOF-MS. Nat Prod Res. 2012;26(2):167-72.

50. Gao N, Cheng S, Budhraja A, Gao Z, Chen J, Liu EH, Huang C, Chen D, Yang Z, Liu Q, et al. Ursolic acid induces apoptosis in human leukaemia cells and exhibits anti-leukaemic activity in nude mice through the PKB pathway. Br J Pharmacol. 2012;165(6):1813-26.

51. Zhang YX, Kong CZ, Wang LH, Li JY, Liu XK, Xu B, Xu CL, Sun YH. Ursolic acid overcomes BCl-2-mediated resistance to apoptosis in prostate cancer cells involving activation of JNK-induced Bcl-2 phosphorylation and degradation. J Cell Biochem. 2010;109(4):764-73.

52. Liu Z, Liu M, Liu M, Li JC. Methylanthraquinone from Hedyotis diffusa WILLD induces $\mathrm{Ca}^{2+}{ }^{2+}$-mediated apoptosis in human breast cancer cells. Toxicol Vitro. 2010;24(1):142-7.

53. Wang N, Li DY, Niu HY, Zhang Y, He P, Wang JH. 2-Hydroxy-3-methylanthraquinone from Hedyotis diffusa Willd induces apoptosis in human leukemic U937 cells through modulation of MAPK pathways. Arch Pharm Res. 2013;36(6):752-8.

54. Sun HD, Huang SX, Han QB. Diterpenoids from Isodon species and their biological activities. Nat Prod Rep. 2006;23(5):673-98.

55. Liu HM, Yan XB, Kiuchi F, Liu ZZ. A new diterpene glycoside from Rabdosia rubescens. Chem Pharm Bull. 2000:48(1):148-9.

56. Bao RF, Shu YJ, Wu XS, Weng H, Ding Q, Cao Y, Li ML, Mu JS, Wu WG, Ding QC, et al. Oridonin induces apoptosis and cell cycle arrest of gallbladder cancer cells via the mitochondrial pathway. BMC Cancer. 2014:14:217.

57. Wang H, Ye Y, Pan SY, Zhu GY, Li YW, Fong DW, Yu ZL. Proteomic identification of proteins involved in the anticancer activities of oridonin in HepG2 cells. Phytomedicine. 2011;18(2-3):163-9.

58. Wang S, Zhong Z, Wan J, Tan W, Wu G, Chen M, Wang Y. Oridonin induces apoptosis, inhibits migration and invasion on highly-metastatic human breast cancer cells. Am J Chin Med. 2013;41 (1):177-96.

59. Hu HZ, Yang YB, Xu XD, Shen HW, Shu YM, Ren Z, Li XM, Shen HM, Zeng HT. Oridonin induces apoptosis via PI3K/Akt pathway in cervical carcinoma HeLa cell line. Acta Pharmacol Sin. 2007;28(11):1819-26.

60. Sun KW, Ma YY, Guan TP, Xia YJ, Shao CM, Chen LG, Ren YJ, Yao HB, Yang $\mathrm{Q}, \mathrm{He} \mathrm{XJ}$. Oridonin induces apoptosis in gastric cancer through Apaf-1, cytochrome $\mathrm{c}$ and caspase-3 signaling pathway. World J Gastroenterol. 2012;18(48):7166-74.

61. Zhu M, Hong D, Bao Y, Wang C, Pan W. Oridonin induces the apoptosis of metastatic hepatocellular carcinoma cells via a mitochondrial pathway. Oncol Lett. 2013;6(5):1502-6.

62. Zang LH, Xu Q, Ye YC, Li X, Liu YQ, Tashiro S, Onodera S, Ikejima T. Autophagy enhanced phagocytosis of apoptotic cells by oridonintreated human histocytic lymphoma U937 cells. Arch Biochem Biophys. 2012:518(1):31-41.

63. Bu HQ, Liu DL, Wei WT, Chen L, Huang H, Li Y, Cui JH. Oridonin induces apoptosis in SW1990 pancreatic cancer cells via p53-and caspasedependent induction of p38 MAPK. Oncol Rep. 2014;31(2):975-82.

64. Liu Y, Liu JH, Chai K, Tashiro SI, Onodera S, Ikejima T. Inhibition of c-Met promoted apoptosis, autophagy and loss of the mitochondrial transmembrane potential in oridonin-induced A549 lung cancer cells. J Pharm Pharmacol. 2013:65(11):1622-42.

65. Dai ZJ, Lu WF, Gao J, Kang HF, Ma YG, Zhang SQ, Diao Y, Lin S, Wang $X J$, Wu WY. Anti-angiogenic effect of the total flavonoids in Scutellaria barbata D. Don. BMC Complement Altern Med. 2013;13:150.

66. Dai ZJ, Wang BF, Lu WF, Wang ZD, Ma XB, Min WL, Kang HF, Wang XJ, Wu WY. Total flavonoids of Scutellaria barbata inhibit invasion of hepatocarcinoma via MMP/TIMP in vitro. Molecules. 2013;18(1):934-50.

67. Lin JM, Chen YQ, Cai QY, Wei LH, Zhan YZ, Shen A, Sferra TJ, Peng J. Scutellaria barbata D Don inhibits colorectal cancer growth via suppression of multiple signaling pathways. Integr Cancer Ther. 2014;13(3):240-8.

68. Lee TK, Lee YJ, Kim DI, Kim HM, Chang YC, Kim CH. Pharmacological activity in growth inhibition and apoptosis of cultured human leiomyomal cells of tropical plant Scutellaria barbata D. Don (Lamiaceae). Environ Toxicol Pharmacol. 2006;21(1):70-9.

69. Suh SJ, Yoon JW, Lee TK, Jin UH, Kim SL, Kim MS, Kwon DY, Lee YC, Kim $\mathrm{CH}$. Chemoprevention of Scutellaria bardata on human cancer cells and tumorigenesis in skin cancer. Phytother Res. 2007;21(2):135-41.
70. Xu HL, Yu JM, Sun Y, Xu XN, Li L, Xue M, Du GH. Scutellaria barbata D. Don extract synergizes the antitumor effects of low dose 5-fluorouracil through induction of apoptosis and metabolism. Phytomedicine. 2013;20(10):897-903.

71. Trachootham D, Alexandre J, Huang P. Targeting cancer cells by ROSmediated mechanisms: a radical therapeutic approach? Nat Rev Drug Discov. 2009;8(7):579-91.

72. Qi FH, Li AY, Inagaki Y, Gao JJ, Li JJ, Kokudo N, Li XK, Tang W. Chinese herbal medicines as adjuvant treatment during chemo- or radio-therapy for cancer. Biosci Trends. 2010;4(6):297-307.

73. Wang ZY, Li GS, Huang HX. Clinical observation on treatment of 75 mid-late stage cancer patients with yanshu injection. Chin I Integr Med. 2006;26(8):681-4

74. She T, Zhao C, Feng J, Wang L, Qu L, Fang K, Cai S, Shou C. Sarsaparilla (Smilax glabra Rhizome) extract inhibits migration and invasion of cancer cells by suppressing TGF- $\beta 1$ pathway. PLOS ONE. 2015;10(3):e0118287.

75. Zhou SK, Zhang RL, Xu YF, Bi TN. Antioxidant and immunity activities of Fufang Kushen injection liquid. Molecules. 2012;17(6):6481-90.

76. Wei R, Yang DY, Jiang WZ, Dai YY, Wan LY, Yang Z. Efficacy of Yanshu injection (a compound Chinese traditional medicine) combined with concurrent radiochemotherapy in patients with stage III nasopharyngeal carcinoma. Chin J Oncol. 2011;33(5):391-4.

77. Lin LT, Wu SJ, Lin CC. The anticancer properties and apoptosis-inducing mechanisms of cinnamaldehyde and the herbal prescription HuangLian-Jie-Du-Tang (Huang Lian Jie Du Tang) in human hepatoma cells. J Tradit Complement Med. 2013;3(4):227-33.

78. Hsu YL, Kuo PL, Tzeng TF, Sung SC, Yen MH, Lin LT, Lin CC. Huanglian-jie-du-tang, a traditional Chinese medicine prescription, induces cell-cycle arrest and apoptosis in human liver cancer cells in vitro and in vivo. J Gastroenterol Hepatol. 2008;23(7):E290-9.

79. Ma Z, Otsuyama K, Liu SQ, Abroun S, Ishikawa H, Tsuyama N, Obata M, Li FJ, Zheng $X$, Maki Y, et al. Baicalein, a component of Scutellaria radix from Huang-Lian-Jie-Du-Tang (HLJDT), leads to suppression of proliferation and induction of apoptosis in human myeloma cells. Blood. 2005;105(8):3312-8.

80. Yuki F, Kawaguchi T, Hazemoto K, Asou N. Preventive effects of orengedoku-to on mucositis caused by anticancer agents in patients with acute leukemia. Gan To Kagaku Ryoho. 2003;30(9):1303-7.

81. Fukutake M, Miura N, Yamamoto M, Fukuda K, lijima O, Ishikawa H, Kubo M, Okada M, Komatsu Y, Sasaki H, et al. Suppressive effect of the herbal medicine Oren-gedoku-to on cyclooxygenase-2 activity and azoxymethane-induced aberrant crypt foci development in rats. Cancer Lett. 2000;157(1):9-14.

82. Cao ZY, Lin W, Huang ZR, Chen XZ, Zhao JY, Zheng LP, Ye HZ, Liu ZZ, Liao LM, Du J. Ethyl acetate extraction from a Chinese herbal formula, Jiedu Xiaozheng Yin, inhibits the proliferation of hepatocellular carcinoma cells via induction of G0/G1 phase arrest in vivo and in vitro. Int J Oncol. 2013:42(1):202-10.

83. Chen XZ, Cao ZY, Li JN, Hu HX, Zhang YQ, Huang YM, Liu ZZ, Hu D, Liao LM, Du J. Ethyl acetate extract from Jiedu Xiaozheng Yin inhibits the proliferation of human hepatocellular carcinoma cells by suppressing polycomb gene product Bmi1 and Wnt/beta-catenin signaling. Oncol Rep. 2014;32(6):2710-8.

84. Chen LW, Lin J, Chen W, Zhang W. Effect of Chinese herbal medicine on patients with primary hepatic carcinoma in III stage during perioperational period: a report of 42 cases. Chin J Integr Med. 2005;25(9):832-4.

85. Tilton R, Paiva AA, Guan JQ, Marathe R, Jiang Z, van Eyndhoven W, Bjoraker J, Prusoff Z, Wang H, Liu SH, et al. A comprehensive platform for quality control of botanical drugs (PhytomicsQC): a case study of Huangqin Tang (HQT) and PHY906. Chin Med. 2010;5:30.

86. Saif MW, Lansigan F, Ruta S, Lamb L, Mezes M, Elligers K, Grant N, Jiang ZL, Liu SH, Cheng YC. Phase I study of the botanical formulation PHY906 with capecitabine in advanced pancreatic and other gastrointestinal malignancies. Phytomedicine. 2010;17(3-4):161-9.

87. Saif MW, Li J, Lamb L, Kaley K, Elligers K, Jiang ZL, Bussom S, Liu SH, Cheng YC. First-in-human phase II trial of the botanical formulation PHY906 with capecitabine as second-line therapy in patients with advanced pancreatic cancer. Cancer Chemother Pharmacol. 2014;73(2):373-80. 
88. Yen Y, So S, Rose M, Saif MW, Chu E, Liu SH, Foo A, Jiang Z, Su T, Cheng YC. Phase I/II study of PHY906/capecitabine in advanced hepatocellular carcinoma. Anticancer Res. 2009;29(10):4083-92.

89. Lam W, Bussom S, Guan F, Jiang Z, Zhang W, Gullen EA, Liu SH, Cheng YC. The four-herb Chinese medicine PHY906 reduces chemotherapyinduced gastrointestinal toxicity. Sci Transl Med. 2010;2(45):45ra59.

90. Greaves M, Maley CC. Clonal evolution in cancer. Nature. 2012;481(7381):306-13.

91. Hsu YL, Kuo PL, Chiang LC, Lin CC. Involvement of p53, nuclear factor kappaB and Fas/Fas ligand in induction of apoptosis and cell cycle arrest by saikosaponin d in human hepatoma cell lines. Cancer Lett. 2004;213(2):213-21.

92. Ashour ML, Wink M. Genus Bupleurum: a review of its phytochemistry, pharmacology and modes of action. J Pharm Pharmacol. 2011;63(3):305-21.

93. Zhu BH, Pu R, Zhang GP, Li MY, Wang LT, Yuan JK. Effect of Saikosaponins-d on reversing malignant phenotype of HepG2 cells in vitro. Chin J Hepatol. 2011;19(10):764-7.

94. Zhang JQ, Li YM, Liu T, He WT, Chen YT, Chen XH, Li X, Zhou WC, Yi JF, Ren ZJ. Antitumor effect of matrine in human hepatoma G2 cells by inducing apoptosis and autophagy. World J Gastroenterol. 2010;16(34):4281-90.

95. Jiang H, Hou C, Zhang S, Xie H, Zhou W, Jin Q, Cheng X, Qian R, Zhang $X$. Matrine upregulates the cell cycle protein E2F-1 and triggers apoptosis via the mitochondrial pathway in K562 cells. Eur J Pharmacol. 2007;559(2-3):98-108.

96. Hong SW, Jung KH, Lee HS, Son MK, Yan HH, Kang NS, Lee J, Hong SS. SB365, Pulsatilla saponin D, targets c-Met and exerts antiangiogenic and antitumor activities. Carcinogenesis. 2013;34(9):2156-69.

97. Zhang Y, Bao J, Wang K, Jia X, Zhang C, Huang B, Chen M, Wan JB, Su H, Wang $Y$, et al. Pulsatilla saponin D inhibits autophagic flux and synergistically enhances the anticancer activity of chemotherapeutic agents against hela cells. Am J Chin Med. 2015;43(8):1657-70.

98. Bhattacharyya B, Panda D, Gupta S, Banerjee M. Anti-mitotic activity of colchicine and the structural basis for its interaction with tubulin. Med Res Rev. 2008;28(1):155-83.

99. Lin ZY, Wu CC, Chuang YH, Chuang WL. Anti-cancer mechanisms of clinically acceptable colchicine concentrations on hepatocellular carcinoma. Life Sci. 2013;93(8):323-8.
100. Jiang CP, Ding H, Shi DH, Wang YR, Li EG, Wu JH. Pro-apoptotic effects of tectorigenin on human hepatocellular carcinoma HepG2 cells. World J Gastroenterol. 2012;18(15):1753-64.

101. Jung SH, Lee YS, Lee S, Lim SS, Kim YS, Ohuchi K, Shin KH. Anti-angiogenic and anti-tumor activities of isoflavonoids from the rhizomes of Belamcanda chinensis. Planta Med. 2003;69(7):617-22.

102. Huang YS, Shi ZM. Intervention effect of Feiji Recipe on immune escape of lung cancer. Chin J Integr Med. 2007;27(6):501-4.

103. Bi L, Jin S, Zheng Z, Wang Q, Jiao Y, You J, Li HG, Tian JH. Inhibitory effect of Feiji recipe on ido induced immune escape on the murine model of Lewis lung carcinoma. Chin J Integr Med. 2016;36(1):69-74.

104. Li S, Wang SM, Yang YB, Liu QO. Effect of Viqi Chutan Recipe on caspase-4 and DNA-PK of cell apoptosis approach in transplanted lung cancer A549 cells in nude mice. J Chin Mater Med. 2015;38(6):1247-50.

105. Wang SM, Lin LZ, Zhou JX, Xiong SQ, Zhou DH. Effects of Yiqi Chutan Tang on the proteome in Lewis lung cancer in mice. Asian Pac J Cancer Prev. 2011;12(7):1665-9.

106. Chen CM, Sun LL, Fang RM, Lin LZ. YiQi ChuTan recipe inhibits epithelial mesenchymal transition of A549 cells under hypoxia. Cell Mol Biol. 2016;62(1):10-5.

107. Wu J, Liu SL, Zhang XX, Chen M, Zou X. Effect of Jianpi Yangzheng Xiaozheng recipe on apoptosis and autophagy of subcutaneous transplanted tumor in nude mice: an experimental study on mechanism. Chin J Integr Med. 2015;35(9):1113-8.

108. Chen XZ, Li JN, Zhang YQ, Cao ZY, Liu ZZ, Wang SQ, Liao LM, Du J. Fuzheng Qingjie recipe induces apoptosis in HepG2 cells via P38 MAPK activation and the mitochondria-dependent apoptotic pathway. Mol Med Rep. 2014;9(6):2381-7.

109. Dong ZP, Hu ZQ, Peng W, Shu ZJ, Cao YM, Lu L. Effects of Baihe recipe on expressions of vascular endothelial growth factor and p53 proteins in tumor tissues of nude mice bearing orthotopically transplanted gastric carcinoma BGC-823. Chin J Integr Med. 2009;7(5):458-62.

110. Nie $X$, Shi B, Ding Y, Tao W. Antitumor and immunomodulatory effects of weikangfu granule compound in tumor-bearing mice. Curr Ther Res Clin Exp. 2006:67(2):138-50.

111. Nie XH, Shi BJ, Tao WY. Inhibitory effect of Weikangfu recipe on growth of mouse $\$ 180$ tumor and its apoptotic induction. China J Chin Mater Med. 2006;31(17):1457-60.

\section{Submit your next manuscript to BioMed Central and we will help you at every step:}

- We accept pre-submission inquiries

- Our selector tool helps you to find the most relevant journal

- We provide round the clock customer support

- Convenient online submission

- Thorough peer review

- Inclusion in PubMed and all major indexing services

- Maximum visibility for your research

Submit your manuscript at www.biomedcentral.com/submit
() Biomed Central 